\title{
Obstetrics and Gynaecology in Arab Medicine
}

\author{
Gamal I. El-Masry, M.D.
}

DOI: http://dx.doi.org/10.5915/17-1-12745

\begin{abstract}
:
The subject deals with an aspect of medical history which is more of general interest than topics about pure gynaecology and obstetrics. The evolution of Arab Medicine started in the 8th century A.D. and its influence was maintained up to the end of the 18th century. There was a large list of names of Arabic authors who wrote about gynecologic and obstetric diseases.

The most eminent author among them were El-Razyi (865-925 A.D.) who wrote the "Continent of Medicine" Aly Ibn Abbas who (died 944 A.D.) wrote "Al-Maliki", Ibn Sina (980-1037 A.D.) who wrote El-Cannon of Medicine and El-Zahrawi (1030-1106 A.D.) who wrote "El-Tasrif".
\end{abstract}

\section{Introduction}

The evolution of Arab Medicine started in the 8th century A.D. and its influence was maintained up to the end of the 18th century.

The early part of this period, the 8 th and 9 th centuries, was the time of translation and compilation; Greek medicine changed into Arabic form.

The golden age of the Arab civilization and Arab Medicine began with the Abbaside Caliphate at Baghdad. The history of Arab Medicine affords us with one of the most interesting studies in the drift of culture of which it is possible to give a systematic and authentic narrative.

There was a large list of names of Arab authors who wrote about gynecologic and obstetric diseases. The most eminent author among them were El-Razyi (865-925 A.D.) who wrote "Al-Hawi" or the "Continent of Medicine"; Aly Ibn Abbas who died in 944 A.D., wrote "Al-Maliki"; Ibn Sina (980-1037 A.D.) wrote "El-Cannon" or "Canon of Medicine" and ElZahrawi (1030-1106 A.D.) wrote "El-Tasrif".

\section{(a) Zakariah Razi (865-925 A.D.)}

In chronological order, the first of these was Zakariah Razi or more fully: Abu Bakr Muhammed Ibn Zakariya El-Razy (865-925 A.D.)!

He was the most celebrated and probably the most original of the Arab writers who followed both Hippocrates and Galen in their methods and ideas. He was a great clinician and ranked with Hippocrates as one of the original portrayers of disease.

From the Department of Obstetrics \& Gynaecology,

Faculty of Medicine, Al Azhar University, Cairo, Egypt,

Presented at the 17th Annual Convention of the Islamic Medical

Association, St. Louis, Missouri, August 10-12, 1984.

Address all correspondence to: Dr. Gamal I. El-Masry

Department of Obstetrics and Gynaecology

Faculty of Medicine

Al Azhar University, Cairo, Egypt.
$\mathrm{He}$ is credited with about 237 works, many of which are lost. "Al-Hawi" or the "Continent of Medicine", the largest and most important of his production, was an encyclopedia of medicine and surgery containing a summary of all branches of the art and science of medicine in 25 books. "The Continent" was translated into Latin in 1280. Latin editions of the Hawi were published in Venice 1506 and 1542.

A perusal of the work of "Rhazes" shows his ingenious and acute observations. He described the signs of menopause, signs of uterine tumor, physiological changes associated with pregnancy, false pregnancy, antenatal care and congenital malformation of the fetus such as imperforate hymen. He also pointed out the line of treatment and obstetrical surgical operations such as extraction of the dead fetus and extraction of the retained placenta.

(b) Ali Ibn Abbas (died 944 A.D.): ${ }^{3}$

Ali Ibn Abbas, was known in the Latin west as Holy Abbas. His principal work was "Al-Kitabu Al Maliki" which was a comprehensive compilation on theoretical and practical medicine in 20 books. He described the anatomy of the uterus and gonads, physiology of menstruation, amenorrhea, leucorrhea, displacement of the uterus, cervical erosion, signs of menopause, tumour

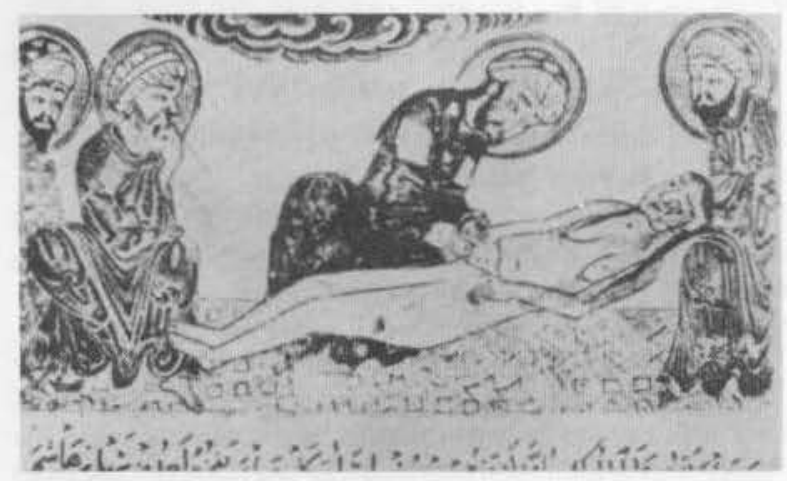

Cesarean section. Miniature from a 1307-1308 Arabian manuscript, al-Athar al Bagiya 
of the uterus, sexology, formation of the fetus from fertilization until its expulsion at the 7 th, or 9 th month, antenatal care, etiology of abortion, normal and abnormal delivery and its management, difficult labour, care of the newborn and lactation.

Al-Maliki is generally regarded as the best work of the Arab period. This royal book was the standard textbook of Arab Medicine until it was replaced by the Canon of Avicenna about a century later.

\section{(c)Abu-Ali Husayn Ibn Abdullah Ibn Sina (980-1037 A.D. $)^{4}$}

He was known in the Latin West as Avicenna or Ibn Sina of the Arabs. He was the most famous of Arab physicians and philosophers. His influence extended throughout the world of Islam and in the West of Europe. The best known of his work is the "Canon of Medicine" called in Arabic "Al-Quanoon-fit-Tib", the most famous textbook of medicine ever written. This work was the final codification of all Greek and Arab Medicine. For more than 6 centuries it was the standard textbook in the medical schools of Asia and Europe. Even as late as the 15 th century in Europe, it has been repeatedly mentioned in 14 editions.

He described the structure of the uterus, physiology of menstruation, amenorrhoea, bleeding, leucarrhoea, displacement of the uterus, uterine and urinary fistula sterility and infertility, contraception, tumour of the uterus, sexology, fetal circulation, physiological changes associated with pregnancy, aetiology of abortion as incompetent cervix and its treatment, aetiology of multiple pregnancy, normal and abnormal delivery. signs of onset of labour, signs of difficult labour and duration of puerperium and its complications as hemorrhage and sepsis. (d) Abu-I-Qasim El-Zahrawi (1030-1106 A.D.) $)^{2}$

$\mathrm{He}$ was the greatest of the surgeons of the Arab period. His principal work was an encyclopedia of medicine and surgery, entitled "El-Tasrif'" which has been translated 5 times. It was the first book on surgery which contained such a large number of illustrations. He described the causes of amenorrhea, causes and clinical picture of dysmenorrhoea, sexology and congenital malformation such as hydrocephalus, its accompanying signs and its treatment. He was the first to point out the possibility of ectopic pregnancy. He also described the management of normal and abnormal delivery such as breech and shoulder presentations or multiple pregnancies. He also described the obstetric posture, now known as "Walcher's" position and mentioned instrumental delivery in parturition.

In conclusion, it can be said that the Arabs were truly pioneers in the Art of Medicine especially in the field of Obstetrics and Gynecology.

\section{REFERENCES}

1. El-Razyi, A.M., Continent of Medicine, manuscript at Egyptian Library under No. 1718 Medicine, 3rd. part, pp. 55-59; 9th part, pp.3-140.

2. El-Zahrawi A.L., El-Tasrif, manuscript at Egyptian Library under No. 566 Medicine 1st part, pp.37-90; 2nd part, pp. 114; 9th part, pp.3-12.

3. Ibn Abbas. A., Al-Kitabu El-Maliki, manuscript at Egyptian Library under No. 1035 Medicine 1st part, sec. 2,3,6,9; ch. $3,33,34,39$.

4. Ibn Sina. A.A.H.I.A., Cannon of Medicine, manuscript at Egyptian Library under No. 1133 Medicine sec. 1st., 2nd., 3rd., 4th.; ch. 20-21, pp. 3-139. 